\title{
Ilmu Pegangan Hidup Seorang Muslim da- lam Kesenian Kentrung Blora, Jawa Tengah
}

Firlie Ni'mah Husnayain

Pendidikan Seni, Pascasarjana UNY

Email: firliehusnayain@gmail.com

S. Sutiyono

Pendidikan Seni, Pascasarjana UNY

Email: sutiono@uny.ac.id

\begin{abstract}
Abstrak
Artikel ini menunjukkan Kentrung Blora yang besar dari hajatan satu ke hajatan lain sebagai pengiring doa telah berubah menjadi sebuah seni pertunjukan kentrung Blora yang sudah bukan hal asing tampil dalam panggung besar di depan khalayak ramai dijadikan salah satu ikon kesenian Blora. Pemerintah mengupayakan agar kesenian ini tetap lestari yaitu dengan memunculkannya sebagai sebuah seni pertunjukan yang bersifat hiburan bagi masyarakat. Nilai edukatif pada pertunjukan kentrung Blora yaitu ajaran ilmu pegangan hidup yang selaras dengan ajaran Walisongo dikemas dalam sebuah cerita babad yang dilengkapi dengan nasihat, doa, dan pantun sebagai warna dalam pertunjukan yang menghibur para penontonnya. Ajaran tersebut bernama "sipat rong puluh" atau "sifat dua puluh" selaras dengan aksara Jawa yang berjumlah dua puluh. Jenis penelitian ini adalah penelitian lapangan dengan pendekatan kualitatif. Metode pengumpulan data dalam penelitian ini dengan tiga cara yaitu, dokumentasi, wawancara dan observasi. Metode analisis data dalam penelitian ini adalah dengan analisis deskriptif. Namun ada dua kali penjabaran "sipat rong puluh" dengan penjelasan berbeda sehingga jumlahnya menjadi empat puluh poin dalam ilmu pegangan hidup Ke empat puluh poin yang dijabarkan sebagai ilmu pegangan hidup tersebut secara khusus adalah untuk seorang muslim. Tetapi karena masih erat kaitannya dengan kepercayaan Jawa, ilmu pegangan hidup tersebut dapat pula diterapkan secara umum bagi setiap manusia untuk memperoleh kehidupan yang seimbang.
\end{abstract}

Kata kunci: ilmu pegangan hidup, kentrung Blora. 


\title{
Muslim's Life Philosophy on Kentrung Art of Blora, Central Java
}

\author{
Firlie Ni'mah Husnayain \\ Pendidikan Seni, Pascasarjana UNY \\ S. Sutiyono \\ Pendidikan Seni, Pascasarjana UNY
}

\begin{abstract}
Blora's kentrung has changed as a performing arts so we can see its performance at big stage not only at small events. It becomes an art icon. The government strives for this art to remain sustainable, by bringing it up as an entertainment art for the people. Its educative values include the teaching of life philosophy in line with Walisongo teachings in a chronicle story supplemented with advice, prayer, and pantun in performances that entertain the audience. It is called "sipat rong puluh" or "the twenty character" in harmony with Javanese script which amounts to twenty. But there are two times the translation of "sipat rong puluh" with different explanations so that the number becomes forty points in the life philosophy, described as life philoshophy in particular for a Muslim. Because it is still closely related to Javanese beliefs that always maintain a balance between humans, God, and nature, it can also be applied in general to every human being to obtain a balanced life.
\end{abstract}

Keywords: the life philosophy, kentrung Blora.

\section{PENDAHULUAN}

Kehadiran Islam di Indonesia tidak lepas dari penyebaran yang dilakukan Walisongo di pulau Jawa sekitar abad 15. Melalui kesenian adalah cara yang Walisongo gunakan untuk mudah menyatu dengan masyarakat. Kesenian tersebut adalah "njantrung" yang kemudian disebarkan ke beberapa daerah seperti Tulungagung, Madiun, Gresik, Tuban, hingga ke seluruh pesisir utara Jawa ${ }^{1}$. Kehadiran kesenian tersebut yang sudah sangat tua masih bisa dirasakan hingga sekarang melalui kesenian kentrung yang diyakini mempunyai kaitan dengan perkembangan kesenian yang Walisongo guna-

1 Eva Nur Inayah, “Bentuk, Makna, Dan Fungsi Tembang-Tembang Kentrung Bate Di Kabupaten Tuban" (Universitas Airlangga, 2015). 
kan sebagai media dakwah tersebut. Kentrung Blora merupakan salah satu kesenian yang ditampilkan oleh seorang dalang sekaligus merangkap sebagai panjak. Dalam pertunjukannya sang dalang bercerita dan bernyanyi sambil memainkan tiga alat musik pukul yaitu satu terbang dan dua ketunthung. Kedua alat musik tersebut berbentuk seperti rebana. Kesenian yang ada sejak tahun 1950-an ini mulai muncul di Blora tepatnya di desa Sendanggayam kecamatan Banjarejo. Hanya satu orang pemain kentrung sejak kentrung ada di Blora hingga seniman tersebut meninggal dan kini diteruskan oleh salah seorang anaknya. Kentrung dapat dijumpai dalam hajatan-hajatan seperti acara kelahiran bayi, pernikahan, dan khitanan. Kentrung dianggap sebagai lambang doa bagi sang pemilik rumah. Saat ini berbagai hajatan yang biasa mengundang kentrung sudah tidak banyak yang menanggap kentrung. Sesekali pemerintah setempat mengundang kentrung untuk tampil dalam peringatan hari-hari penting dan festival kesenian sebagai upaya pelestarian. Seperti pada 14 September 2018 lalu kentrung tampil di alun-alun Blora. Sayang, kesenian yang pernah besar di masyarakat melalui hajatan satu ke hajatan yang lain, kini sudah tidak sesering itu masyarakat mengundang kentrung sebagai hiburan dalam acara mereka.

Selain sebagai lambang doa, fungsi lain kesenian kentrung ialah sebagai media dakwah. Kentrung tersebar di berbagai daerah Jawa Timur dan Jawa Tengah. Salah satu daerah yang mempunyai kesenian kentrung ialah daerah Blora, Jawa Tengah. Bagi masyarakat sekitar, kentrung Blora tidak sekedar media dakwah melainkan juga perwujudan doa atau keinginan, ucapan syukur, hiburan, dan lain-lain. Sebagai media dakwah apa yang kentrung berikan kepada penontonnya? Artikel ini akan menjabarkan muatan dalam kesenian kentrung Blora sebagai sebuah media dakwah Islam di masa lampau yang masih hingga bertahan hingga saat ini.

\section{METODOLOGI}

Jenis penelitian ini adalah penelitian lapangan dengan pendekatan kualitatif. Tempat penelitian ini dilakukan di Blora Jawa Tengah. Sumber data penelitian ini adalah data primer dan sekunder yaitu ajaran ajaran yang tersirat dalam kesenian kentrung. Metode pengumpulan data dalam penelitian ini dengan tiga cara yaitu, dokumentasi, wawancara dan observasi. 
Metode analisis data dalam penelitian ini adalah dengan analisis deskriptif yaitu menjabarkan temuan-temuan penelitian dengan bahasa dan kata-kata atau narasi. Untuk menguji keabsahan data dalam penelitian ini juga dilakukan dengan teknik triangulasi sumber.

\section{PEMBAHASAN}

\section{Sejarah Kesenian Kentrung Blora}

Kentrung Blora merupakan sebuah pertunjukan kesenian tradisional rakyat yang mempunyai dua unsur seni yaitu seni musik dan seni sastra. Unsur seni musiknya ialah vokal dan instrumen sebagai iringan. Unsur seni sastranya ialah teks yang diucapkan dalam pertunjukan tersebut.

Pemain dalam pertunjukan kentrung Blora hanyalah seorang bapak yang diberi sebutan mbah kentrung. Mbah kentrung akan menceritakan babad atau sejarah yang ditulis dengan cara pandang tradisional, sehingga dibumbui dengan berbagai mitos, legenda, dan sebagainya. Sejarah yang diceritakan pada pertunjukan ini ialah kisah nabi-nabi dan wali sanga. Masing-masing cerita memiliki judul atau juga disebut lakon. Beberapa lakon di antaranya Lahire Kanjeng Nabi Ibrahim, Lahire Kanjeng Nabi Musa, Yusuf dadi Ratune Kraton Negara Mesir, Babade Tanah Jawa Jejera Negara Tuban, Lakon Mekkah Mumammad, Lakon Babade Tanah Jawa Wilatikta, dan lain-lain.

Cerita tersebut akan dinyanyikan dengan nada dan cengkok khas kesenian ini dengan diiringi tiga alat perkusi seperti rebana bernama terbang yang memiliki ukuran berbeda-beda. Terbang adalah nama untuk yang berukuran besar sedangkan yang kecil adalah ketunthung. Rebana memang tersebar di berbagai daerah tetapi masing-masing daerah mempunyai cara penyebutan yang berbeda seperti trebana, terbang, trebang, rabana, robana, dan lain-lain ${ }^{2}$. Salah satu khas nyanyian dalam pertunjukan kentrung ialah "nano nano nane" yang bisa dibalik menjadi "nano nane nano", "nano nane nane", dan lain-lain.

Awal mula keberadaan kentrung Blora ialah pada tahun 1958, pak Sutrisno, seorang pria berusia tiga puluh lima tahun berasal dari daerah Mintreng

2 Karl Edmund Prier, Kamus Musik (Yogyakarta: Pusat Musik Liturgi, 2011). 
Gubug di kabupaten Demak yang mengaji di pondok pesantren Kalituri yang juga masih dalam kabupaten sama. Dinyatakan lulus sebagai santri pondok pesantren, beliau diminta untuk mengajar di sana. Namun beliau merasa menjadi guru di pondok pesantren tidaklah sesuai dengan kata hatinya yang justru memilih berkelana untuk mencari jati dirinya supaya kelak dapat menjadi diri yang dapat diterima dengan baik oleh yang kuasa. Sampai pada akhirnya suatu ketika pak Sutrisno nabuh atau memainkan kentrung. Beliau mempunyai kebisaan atau istilah dalam bahasa Jawa kebakitan untuk menabuh kentrung. Saat itu tidak ada yang tahu bahkan murid-murid beliau sekalipun. Selanjutnya pak Sutrisno memutuskan untuk keluar dari pondok tersebut.

Hijrah ke sebuah desa yang menjadikan pertunjukan kentrung justru disenangi masyarakat dan dipercaya dapat menjadi wujud doa bagi yang mempunyai keinginan yaitu desa Sendanggayam kecamatan Banjarejo kabupaten Blora. Pertunjukan ini pertama kali tampil di depan khayalak umum saat ada seorang tetangga yang mengadakan syukuran pupakan bayi yaitu syukuran atas lepasnya tali pusar bayi yang baru lahir dan mengundang pak Sutrisno untuk ngentrung dalam acara tersebut. Kentrung memang tidak terbatas pada cerita melainkan juga perwujudan doa bagi para penanggap yang mempunyai murwa kala atau tujuan dan mempercayai dengan adanya kentrung dalam acara mereka maka tujuan tersebut akan tercapai. Selain syukuran pupakan bayi, pertunjukan kentrung dapat hadir dalam acara syukuran khitanan, pernikahan, dan seseorang mempunyai nazar khusus. Penanggap akan mengundang mbah kentrung dalam acara mereka dan melalui gethok tular (mulut ke mulut) masyarakat akan datang untuk menyaksikan. Sesekali pemerintah setempat mengundang kentrung untuk tampil dalam peringatan hari-hari penting dan festival kesenian sebagai upaya pelestarian.

Masyarakat penonton pertunjukan kentrung mayoritas ialah bapak-bapak dan ibu-ibu yang sudah dapat dikatakan tua. Ada juga anak muda yang menonton terutama saat kentrung menjadi bagian dalam acara yang diadakan pemerintah seperti Festival Kesenian Asli Blora. Bagi bapak-bapak dan ibu-ibu yang sejak muda menganggap kentrung sebagai salah satu hiburan yang mereka senangi, sampai saat ini mereka sudah tua pun kentrung masih ditunggu-tunggu. Selalu datang setiap kali mendapat informasi bahwa akan 
ada pertunjukan kentrung. Mereka menyenangi kentrung sebagai hiburan yang tendensinya pada syiar agama. Mereka tertarik untuk mendengarkan cerita yang dibawakan mbah kentrung. Mereka juga merasa dapat memahami sejarah salah satunya melalui cerita mbah kentrung. Ketoprak dan barongan hiburan hanya untuk bersenang-senang sedangkan kentrung tidak sekadar itu. Saat ini sudah jarang, jika ada, mereka akan hadir.

Pertunjukan kentrung merupakan sebuah kesenian rakyat yang tampil dari satu hajatan ke hajatan lain. Kemasannya relatif sederhana karena pemain kentrung hanya satu orang. Alat musik yang digunakan hanya tiga buah terbang. Hal tersebut menjadikan beberapa unsur dalam penyajiannya tidak mempunyai pakem khusus. Mbah kentrung sangat mudah menyesuaikannya. Begitu juga dengan waktu dan durasinya. Pagi, siang, sore, atau malam menyesuaikan dengan keinginan penanggap. Hajatan di malam hari biasanya akan dimulai pukul 21.00-24.00. Durasi ini tidak pakem, jika penanggap ingin berlangsung lebih singkat pun bisa.

\section{Fungsi Kesenian Kentrung Blora}

a. Sebagai Sarana Ritual

Sebuah pertunjukan yang utuh kentrung mencakup cerita sejarah, doa, nasihat, dan hiburan. Keberadaannya dalam sebuah hajatan sangat dekat kaitannya dengan situasi yang terjadi pada seseorang atau penanggap yang menginginkan adanya pertunjukan ini ditampilkan. Kentrung merupakan sarana ritual bagi penanggap yang mempunyai keinginan. Para penanggap meyakini bahwa pertunjukan yang digelar adalah wujud doa mereka yang disampaikan oleh mbah kentrung kemudian akan diamin-kan oleh para penonton yang datang. Acara tersebut antara lain:

1) Kelahiran Bayi

Dalam tradisi masyarakat Jawa, syukuran atas kelahiran bayi ialah saat tali pusar bayi lepas, dalam bahasa Jawa disebut puputan, masyarakat Blora menyebutnya dengan pupakan. Biasanya orang tua bayi akan mengadakan acara di rumahnya dan mengundang tetangga sekitar untuk datang. Di acara tersebutlah, pertunjukan kentrung diselenggarakan atas keinginan orang tua bayi. Masyarakat desa masih mempunyai kebiasaan untuk menyebarkan dari mulut 
ke mulut, sehingga rumah orang tua bayi akan ramai didatangi oleh masyarakat yang ingin menyaksikan pertunjukan kentrung. Selain wujud syukur, kentrung juga wujud doa orang tua agar anaknya dapat menjadi anak yang baik dan sukses di kemudian hari.

2) Khitanan

Khitan bagi laki-laki terdiri dari operasi pengangkatan beberapa, atau semua, dari kulup (atau kulup) dari penis ${ }^{3}$. Menurut Al-Hasan ${ }^{4}$ khitan yaitu memotong kulup atau bagian kulit sekitar kepala zakar pada anak laki-laki, atau bagian kulit yang menonjol di atas pintu vagina pada anak perempuan. Diriwayatkan dari Abu Hurairah ra bahwa Rasulullah saw bersabda: "Fitrah itu lima: khitan, mencukur rambut kemaluan, memendekkan kumis, memotong kuku, mencabut bulu ketiak" (HR. al-Bukhari, Muslim). Khitan wajib hukumnya bagi kaum pria, dan rnustahab (dianjurkan) bagi kaum wanita. Selain anjuran medis dan agama khitanan juga merupakan bagian dari tradisi masyarakat. Banyak daerah di Indonesia yang mempunyai tradisi unik bahkan besar-besaran untuk merayakan hajatan khitanan, di kabupaten Bima, Yogyakarta, Jawa Timur, Aceh selatan, dan masih banyak lagi. Ada yang dengan arak-arakan ada juga yang ditandai dengan hidangan yang khas. Upacara khitanan di Jawa Tengah termasuk Blora ini cukup sederhana yaitu mengundang kerabat dan tetangga untuk berdoa bersama disertai dengan hidangan yang khas. Pada hajatan tersebutlah kentrung ditampilkan. Selain rasa syukur orang tua dari anak yang dikhitan, kentrung merupakan wujud doa untuk kesuksesan anak di masa yang akan datang.

3) Pernikahan

Beberapa hiburan yang disajikan oleh tuan rumah yang mengadakan pesta pernikahan memang banyak macamnya. Pertunjukan wayang kulit misalnya, berlangsung semalam suntuk. Pertunjukan kentrung juga dapat belangsung demikian. Di antara rangkaian

3 Policy Statenent Circumcision, "Pediatrics" 130 (September 2012).

4 Yusuf Muhammad Al-Hasan, Pendidikan Anak Dalam Islam (Jakarta: Darul Haq, 1998). 
upacara adat pernikahan akan ada satu malam saat pemilik acara membuat ruang hiburan yang diperuntukkan bagi masyarakat sekitarnya. Pada umumnya ialah malam hari setelah paginya berlangsung resepsi pernikahan. Setelah info tersebar akan ada hiburan tersebut, maka orang-orang akan berkumpul untuk menyaksikannya. Biasanya berlangsung sekitar pukul 21.00-24.00. Kentrung diyakini sebagai doa untuk pengantin agar rumah tangga mereka akan selalu bahagia sekaligus memberi hiburan kepada para kerabat dan tetangga.

\section{b. Sebagai Ungkapan Pribadi ${ }^{5}$}

Ketiga fungsi di atas yaitu kelahiran bayi, khitanan, dan pernikahan selain sebagai sarana ritual di sisi lain juga merupakan ungkapan pribadi atau hiburan bagi penanggap maupun masyarakat yang menonton. Acara atau hajatan lain yang menunjukkan fungsinya sebagai ungkapan pribadi adalah nadzar.

Nadzar secara bahasa berarti mewajibkan (al-ijab), mewajibkan diri sendiri untuk berbuat sesuatu ${ }^{6}$. Masyarakat sering melakukan ini sebagai janji jika mendapatkan sesuatu misalnya saat mengikuti tes ujian masuk sekolah apabila ia lolos ia akan menyumbangkan lima puluh kotak nasi untuk kaum duafa. Maka setelah ia dinyatakan diterima di sekolah yang ia inginkan ia akan memenuhi nadzar tersebut.

Ada kalanya masyarakat Blora dan sekitarnya mempunyai nadzar untuk menyajikan pertunjukan kentrung apabila keinginannya terwujud. Berdasarkan wawancara dengan mbah kentrung, beliau pernah ditanggap oleh seorang pejabat daerah Sragen yang ber-nadzar apabila jabatannya naik. Kentrung menjadi ungkapan pribadi pejabat daerah tersebut.

5 Dinyatakan pula yang termasuk ke dalam kategori pernyataan ungkapan pribadi seperti ekspresi, pernyataan estetis terhadap kesenian atau tradisi yang ada, sebagai perlambangan atas suatu kejadian, ungkapan dari reaksi jasmani yang bergerak dalam melakukan kesenian kentrungan, sebagai salah satu upaya pengendalian sosial, dan lain sebagainya. Baca juga Arum Kusuma Dewi, Sriyanto, and Suharti, "Fungsi Kesenian Kentrungan Di Nagari Sialanggaung Kec. Koto Baru Kab. Dharmasraya," Laga-Laga Vol. 4, no. 2 (September 2018): hlm. 192-196.

6 Fuad Thohari, Hadis Ahkam: Kajian Hadis-Hadis Hukum Pidana Islam (Hudud, Qishash, Dan Ta'zir) (Yogyakarta: Deepublish, 2016). 


\section{c. Hiburan}

Begitu penting pertunjukan kentrung bagi penanggap yang mempunyai keinginan khusus dalam hidupnya yang ia sampaikan melalui kentrung. Tapi tetap saja ini adalah pertunjukan yang terbuka untuk umum, dapat disaksikan masyarakat luas. Walau tanpa undangan formal, saat pertunjukan ini akan ditampilkan dengan kabar dari mulut ke mulut maka seluruh warga sekitar akan datang. Cerita sejarah yang mempunyai kesan mengasyikkan sendiri bagi sebagian orang merupakan hiburan yang mereka harapkan tiap kali datang ke pertunjukan kentrung. Mbah kentrung mengimbangi penampilannya dengan pantun jenaka atau sekedar usil menyindir penonton. Begitu khas dari kentrung, hiburan yang juga memberi pengetahuan cerita sejarah. Di blora ada kesenian lain seperti barongan dan tayub yang bisa jadi lebih atraktif dan menghibur tetapi tidak ada yang bisa penonton bawa pulang selepas itu.

\section{d. Komunikasi}

Pertunjukan kentrung menjadi sarana komukasi antara mbah kentrung kepada para penonton yaitu komunikasi untuk menyampaikan wawasan berupa cerita sejarah dan dakwah agama Islam. ${ }^{7}$ Tercermin dari syair yang disampaikan mbah kentrung. Setiap penampilannya ada lakon untuk diceritakan yaitu seputar sejarah keislaman secara umum maupun tentang penyebarannya di pulau Jawa. Dengan cerita tersebut masyarakat secara tidak langsung akan menambah wawasan tentang sejarah dan agama. Penonton pulang tidak hanya membawa tawa tetapi juga menambah pemahamannya untuk menjadi seorang muslim yang lebih baik dengan melaksanakan perintah agama seperti yang disampaikan mbah kentrung. Bukan berarti sepulang dari menonton pertunjukan kentrung setiap orang akan menjadi seorang muslim yang taat melainkan semakin sering mereka datang menonton dan mendengarkan akan memperkuat pemahaman mereka. Salah satu cuplikan syairnya adalah sebagai berikut. 
Sebab biyen kuwi nek wong salat seket wektu

Sing sak grombol dijupukake dununge sipat telung puluh

Sing sak grombol dununge sipat rong puluh

Sebab dulu itu kalau orang salat lima puluh waktu

Yang satu kelompok diambilkan dari pemahaman sifat tiga puluh

Yang satu kelompok diambilkan dari pemahaman sifat dua puluh

Maksud dari syair tersebut ialah ingin menjelaskan awal mula perintah salat lima waktu yang saat pertama kali perintah itu diberikan ialah salat lima puluh waktu. Salat lima waktu ialah salah satu perintah dalam agama Islam yang apabila ditinggalkan maka akan berdosa. Perintah tersebut turun langsung dari Allah SWT di malam Isra' Mi'raj yaitu malam ketika Nabi Muhammad saw dinaikkan sampai ke Sidratul Muntaha yang merupakan tempat tertinggi batas antara alam syahadah dengan alam gaib. Sahabat Anas bin Malik ra berkata: "Salat difardhukan atas Nabi saw. pada malam Isra' lima puluh (kali) kemudian dikurangi sehingga dikurangi menjadi lima (kali) lalu diserukan: Ya Muhammad, keputusan ini di sisi-Ku tidak dapat diubah dan bagimu yang lima ini adalah lima puluh (kali pahalanya)". (HR Ahmad, an-Nasai, dan atTarmidzi). "Sesungguhnya salat itu adalah kewajiban yang ditentukan waktunya atas orang-orang beriman." (an-Nisa': 103).

Mbah kentrung menyampaikan itu dalam syairnya dan mengaitkannya asal mula angka lima puluh menjadi lima dengan cerita di Jawa. Disebutkan bahwa "Sing sak grombol dijupukake dununge sipat telung puluh, Sing sak grombol dununge sipat rong puluh" ("Yang satu kelompok diambilkan dari pemahaman sifat tiga puluh, Yang satu kelompok diambilkan dari pemahaman sifat dua puluh"). Tiga puluh sifat tidak diceritakan sedangkan dua puluh sifat dijabarkan yang ternyata merupakan uraian makna aksara Jawa yang berjumlah dua puluh. Bisa dipecah lagi menjadi empat: (1) ha na ca ra ka, (2) da ta sa wa la, (3) pa dha ja ya nya, (4) ma ga bat ha nga. Dua puluh dibagi empat sama dengan lima. 
e. Memperkuat Komformitas Norma-norma Sosial

Norma sosial merupakan salah satu yang membentuk sistem sosial untuk mengatur dirinya dalam kehidupan sosial berkaitan dengan yang boleh dan tidak boleh dilakukan ${ }^{8}$. Salah satu norma sosial yang terdapat dalam syair kentrung adalah berikut ini.

Lan iki dina ndak sawang wis kaya meh ngadepna jaman pengadilan pribadi ngger putraningsun kowe Apa sing dimaksudna "jaman pengadilan pribadi", ngger?

Nomer siji anak kudu nggugu jare wong tuwa

Murid aja nganti nglerwakake piwulange bapa guru

Hari ini saya lihat sudah seperti hampir mengahadapi jaman pengadilan pribadi, $n d u k$.

Apa yang dimaksud dengan "jaman pengadilan pribadi"?

Nomor satu, anak harus mengikuti perkataan orang tua

Murid jangan sampai menyepelekan ajaran guru

Dua hal yang ingin disampaikan pada syair tersebut yaitu harus mengikuti perkataan orang tua dan murid tidak boleh menyepelekan ajaran guru. Kedua ajaran tersebut telah diajarkan dan ditanamkan di sekolah melalui mata pelajaran pendidikan kewarganegaraan dan agama. Dalam Islam beberapa hadis telah menyebutkan. Rasulullah saw berkata, "Bukanlah termasuk golongan kali, orang yang tidak menghormati orang yang tua, tidak menyayangi yang muda, dan tidak mengerti hak ulama kami" (HR. al-Bazzar 2718, Ahmad 5/323, lafadz milik al-Bazzar. Dishahihkan al-Albani dalam Shohih Targhib 1/117). Imam Nawawi rahimahullah berkata, "Hendaklah seorang murid memperhatikan gurunya dengan pandangan penghormatan. Hendaklah ia meyakini keahlian gurunya dibandingkan yang lain. Karena hal itu akan meng-

8 Patra Zen and Daniel Hutagalung, Panduan Bantuan Hukum Di Indonesia: Pedoman Anda Memahami Dan Menyelesaikan Masalah Hukum, (Jakarta: Yayasan Obor Indonesia, 2007); Baca juga Dewi, Sriyanto, and Suharti, "Fungsi Kesenian Kentrungan Di Nagari Sialanggaung Kec. Koto Baru Kab. Dharmasraya," hlm. 192-196. 
hantarkan seorang murid untuk banyak mengambil manfaat darinya, dan lebih bisa membekas terhadap apa yang ia dengar dari gurunya tersebut" (al-Majmu' 1/84) ${ }^{9}$. Islam memberi penghargaan yang tinggi terhadap guru. Dua keutamaan guru ialah ketinggian ilmunya dan jasanya dalam mengajarkan ilmunya kepada murid. Maka anak harus diajarkan adab murid terhadap guru ${ }^{10}$.

Kedua cuplikan syair tersebut dapat terlihat fungsi kentrung sebagai menambah wawasan dan media dakwah Islam. Kesenian ini sudah ada sejak masyarakat di kecamatan Banjarejo masih kental dengan kejawen dan mereka belum mengenal agama apapun. Pernikahan misalnya, dapat terlaksana tanpa adanya ijab kabul yang disaksikan oleh naib dan hanya disaksikan oleh kehadiran pihak orang tua masing-masing mempelai, itu sudah dianggap sah. Pendidikan agama belum masuk secara utuh kepada seluruh masyarakat. Tidak ada tempat-tempat ibadah di sekitar mereka. Sampai pada akhirnya sekitar tahun 1960 lingkungan mereka kedatangan sebuah lembaga agama dari pemerintah yang memberi bekal pendidikan agama kepada masyarakat sekitar. Masyarakat diajarkan syahadat dan salat serta diadakannya nikah masal yang kemudian pernikahan mereka menjadi tercatat secara resmi di pemerintah. Sejak saat itu kepedulian masyarakat untuk hidup beragama meningkat, khususnya agama Islam. Mushola dan masjid mulai banyak dibangun. Dengan situasi seperti itu, keberadaan kentrung semakin membantu meningkatkan pemahaman masyarakat terhadap agama Islam.

\section{f. Sumbangan pada Pelestarian serta Stabilitas Kebudayaan}

Keberadaan kesenian kentrung yang sudah kurang diminati ini menjadikan pemerintah daerah melakukan upaya-upaya agar kesenian ini tetap lestari. Pertunjukan kentrung ialah mengisi acara yang diadakan pemerintah daerah. Acara tersebut antara lain adalah sebagai berikut.

9 Anwar Sani, Tirmidzi As-Shidiq, and Ahmad Jameel, Belajar Dari Ustadz Yusuf Mansur, (Jakarta: Gramedia, 2013).

10 Wendi Zarman, Ternyata Mendidik Anak Cara Rasulullah Mudah E Efektif (Jakarta: Kawan Pustaka, 2017). 
1) Memperingati Hari-hari Penting.

Pemerintah daerah akan melibatkan pertunjukan kentrung dalam acara hari-hari penting seperti Hari Ulang Tahun Rebuplik Indonesia (HUT RI) dan Hari Jadi Kabupaten Blora. Kedua acara tersebut merupakan acara dengan skala besar yang sangat penting dan ditunggu-tunggu oleh masyarakatnya. Masyarakat Blora memang masih mempunyai ketertarikan yang tinggi tehadap seni tradisional. Barongan, wayang, tayub yang secara kemasan jauh lebih meriah dan menghibur jika dibandingkan dengan kentrung menjadikan pemerintah untuk terus menampakkan kentrung ke permukaan dengan selalu aktif mengundang dalam acara pemerintah.

2) Festival Kesenian Asli Blora

Festival tersebut ialah salah satu acara skala besar di Blora. Festival tersebut pernah berlangsung berbarengan dengan Festival Barongan Nusantara. Saat Blora menjadi tuan rumah, saat itu juga pemerintah menghadirkan Festival Kesenian Asli Blora. Acara yang berlangsung di alun-alun yang sangat luas dengan panggung yang sangat megah, pak Yanuri, mbah kentrung ikut memeriahkan festival tersebut. Walaupun antusiasme masyarakat tak sebesar saat kesenian lain ditampilkan. Dalam festival tersebut yang ditampilkan sebagai kesenian asli Blora ialah barongan, kentrung, dan wayang krucil yaitu seperti wayang kulit tetapi berukuran kecil. Barongan bak ikon kabupaten Blora. Banyak sekali peminatnya. Berdasarkan ketertarikan penonton, barongan menduduki posisi pertama dan kentrung yang terakhir, paling sedikit penontonnya.

\section{Ilmu Pegangan Hidup Dalam Kesenian Kentrung Blora}

Di setiap penampilannya, mbah kentrung dapat menceritakan alur yang berbeda-beda sesuai dengan lakon yang dibawakan. Tetapi terdapat pola yang selalu sama. Ada unsur-unsur yang selalu sama muncul dan dapat diamati saat pertunjukan berlangsung. Jika syair yang dinyanyikan mbah kentrung tersusun sebuah teks pola akan tampak juga. 
Berdasarkan teks terdapat beberapa pola isi dari pertunjukan itu seperti salam pembuka, pantun untuk meminta istirahat, "sipat rung puluh", doa, dan salam penutup. Lima hal tersebut mbah kentrung mengucapkannya dengan kalimat yang hampir selalu sama maka disebut pola. Sedang isi cerita, alur, dan pantun-pantun bisa saja berubah kalimatnya namun dengan makna sama.

"Sipat rong puluh" atau jika diterjemahkan ke dalam bahasa Indonesia adalah "sifat dua puluh". Yang dimaksud dengan "sipat rong puluh" adalah ajaran tentang ilmu pegangan hidup tersebut selaras dengan aksara Jawa yang berjumlah dua puluh HA NA CA RA KA DA THA SA WA LA MA GA BA THA NGA PA DHA JA YA NYA. Namun ada dua kali penjabaran "sipat rong puluh" dengan penjelasan berbeda sehingga jumlahnya menjadi empat puluh poin dalam ilmu pegangan hidup yaitu sebagai berikut

Nek aksara Jawa sing nomer siji

Nek jaman bebujan kuwi isa muni 'hong wilaheng'

Nek aksara Jawa kuwi bisa muni 'hananingsun'

Nek aksara Jawa kuwi ki isa sejatine 'aku ana', ya mas ya ngger.

Adapun aksara Jawa yang pertama ' $H A$ ' pada masa lampau oleh pengaruh agama Hindu dapat dimaknai sebagai lambang bunyi 'hong wilaheng' yang merupakan bentuk perubahan bunyi dari 'aum awighnam'. Kini oleh pengaruh tasawuf (Islam) dapat dimaknai sebagai lambang bunyi 'hananingsun; kesaksian wujud Allah'.

Kaping loro nek aksara 'NA', nata dadi carakaningsun. Aksara kedua 'NA' artinya 'dinobatkan menjadi utusan Allah', dalam konteks ini adalah Nabi Muhammad.

Kaping telu nek aksara ' $C A$ ', carane lambang rasa. Aksara ketiga ' $C A$ ' bermakna 'caranya mengacu kepada rasa'.

Kaping papat nek aksara 'RA', rasa lan karep kudu saeka. Aksara keempat ' $R A$ ' yang maknanya 'perasaan dan kehendak haruslah menyatu'.

Kaping lima nek aksara 'KA', karep kang nedya utama. Aksara kelima 'KA' yang artinya adalah 'bahwa kehendak yang dimaksud di atas tadi adalah kehendak yang mulia'. 
Nanging sing duwe pengadilan awas kudur kuwi aksara ' $R A^{\prime}$

Nanging manjinge ning pucuke irung sak nalika

Nek aksara sing nomor papat kuwi ora tau garah karo kancane, nek ditakoni apik ya mambu apik, ditakoni ala ya mambu ala, ya mas ngana

Iku bagiane aksara 'RA' sebab aksara 'RA', 'gemanjinge pucuk irung'

Irung kuwi ora tau garah, nek ditakoni apik ya mambu apik, nek ditakoni ala ya mambu ala

Iku bagiane aksara 'RA' sing nomer papat sak nalika, ya mas ya

Namun yang memiliki kemampuan menilai kemuliaan dan/atau keutamaan secara adil adalah aksara ' $R A^{\prime}$ ' (aksara keempat): kedudukannya di ujung hidung. Aksara ke-empat tersebut tidak pernah berdusta kepada orang lain. Apabila sesuatu yang ditanyakan dan dikatakan baik maka tentu juga beraroma wangi dan apabila sesuatu yang dipersoalkan disebut buruk maka tentu juga berbau busuk. Begitulah adanya.

Kaping lima nek aksara 'KA', karep kang nedya utama ya kuwi 'gumanjinge ning pucuke kuping'

Sebab kuping sing kiwa, nek ditakoni apik sing tengen muni ala, nek sing tengen ditakoni ala sing kiwa muni apik kuwi bagiane kuping

Nanging aksara ' $K a$ ' sing nomer lima kuwi pendawuhane nggarai bature dewe, ya mas ya ngger

Pada karo awan-awan kilon-kilon mbukak peti raono iwake

Kebangeten wis ngundang mbah dukun anake wis metu ra ditunggoni karo bapake, ya ngger ya

Aksara kelima ' $K A$ ', kehendak perihal keutamaan yang kedudukannya di ujung telinga. Apabila telinga kiri ditanya kebaikan maka telinga kanan menyatakan keburukan. Begitu pula sebaliknya. Begitulah adat telinga yang menjadi induk kehendak sebagai makna aksara ' $K A^{\prime}$ ' (aksara kelima): suka berdusta kepada orang lain. Akan sama halnya dengan perumpamaan per- 
istiwa di tengah siang yang terik telanjur membuka peti ternyata tak ada ikannya; sungguh keterlaluan, dukun bayi sudah berhasil menolong kelahiran bayi justru ayah si bayi tidak menyaksikan.

Kaping enem nek aksara 'DA' sak nalika. Aksara 'DA', dadia tataran, mas mas mas. Aksara keenam ' $D A$ ' yang maknanya 'semogalah dapat dijadikan tahapan'.

Kaping pitu nek aksara 'TA', tataran murih sawiji. Aksara ketujuh adalah aksara ' $T A$ ' yang maknanya 'tahapan agar menyatu'.

Kaping wolu nek aksara 'SA', sawiji kuwayanganingsun. Aksara kedelapan 'SA' yang maknanya adalah 'menyatu/melekat kepada bayangan (hakikat) Tuhan'.

Kaping sanga nek aksara 'WA', wayanganingsun katon malela. Aksara kesembilan 'WA' yang maknanya adalah 'bayangan (hakikat) Tuhan tampak jelas'.

Kaping sepuluh aksara 'LA', langgeng murih karios sapadha-padha. Aksara kesepuluh ' $L A$ ' yang maknanya 'langgeng lestari berdarma bagi sesama'.

Kaping sewelas nek aksara 'PA', padhane rasa kadadha. Aksara kesebelas ' $P A$ ' yang maknanya 'rasa persamaan di dalam kemanusiaan telah dijiwai bersama'.

Kaping rolas nek aksara 'DHA', dedhasar karya prasaja. Ke-duabelas adalah aksara 'DHA' yang maknanya 'segala darma bakti disesuaikan dengan kemampuan pribadi sehingga tidak berlawanan dengan prinsip kesederhanaan dan kejujuran'.

Kaping telulas nek aksara ' $J A$ ', jaya sak jagad raya. Aksara ketigabelas ' $J A^{\prime}$ yang maknanya 'selamat dan berhasil seluruh penghuni alam raya'.

Kaping patbelas nek aksara ' $Y A$ ', yasa karya murih wilujeng ning alam donya. Aksara keempatbelas ' $Y A^{\prime}$ ' yang maknanya 'berbuat demi keselamatan hidup di dunia'.

Kaping limalas nek aksara 'NYA', nyata eling lan sak sama-sama. Aksara kelimabelas ' $N Y A$ ' yang maknanya 'sungguh selalu ingat peduli kepada sesama'.

Kaping nembelas nek aksara ' $M A$ ', maratah sak jagad raya, ya mas ya ngger. Ke-enambelas adalah aksara ' $M A$ ' yang maknanya 'sikap kepedulian itu merata melingkupi semesta'. 
Kaping pitulas nek aksara 'GA', gagaran mung karya prasaja. Aksara ketujuhbelas ' $G A^{\prime}$ ' yang maknanya 'adapun pedomannya ialah berbuat baik semampunya, tanpa dipaksakan dan tanpa rekayasa muslihat'.

Kaping wolulas nek aksara ' $B A$ ', bathara kang wajib amisesa. Aksara kedelapanbelas ' $B A$ ' yang maknanya 'atas semua perbuatan kita Tuhanlah yang berwenang menentukan ganjarannya'.

Kaping sangalas aksara 'THA', tharithisan lali lamun ing ngarsa. Aksara kesembilanbelas ' $T H A^{\prime}$ ' yang maknanya adalah 'adapun adatnya orang menjadi lupa diri jika punya posisi'.

Kaping rong puluh aksara 'NGA', ngawuningani sak mublak-mublike sak budi pakartine, jalma menungsa. Aksara keduapuluh adalah aksara 'NGA' yang maknanya 'adat manusia juga sering alpa atas kekuasaan Tuhan yang Maha Mengetahui segala perbuatan dan pikiran makhluknya'.

Lan aku iki ya kuwi bakal ngudi kawruh sing diarani ngilmu paugeraning gesang

Ya aku iki bakal yo kuwi golek sing diarani kanggo isine ya kuwi sekujur balung sum-sum menyang ning sak tengahing wana sak nalika, ya mas ya Lan diwulang marang bapa guru kula Sunan Bonang Lan dewekne mengko yen bakal diwulang yen wis bisa Wis lulus sing dadi ujiane bakal diwisuda klawan bapa guru sak nalika

Itulah ilmu pegangan hidup yang Sunan Bonang berikan hingga paham kepada muridnya yang akan dinyatakan lulus apabila telah mengerti.

Sebab ning tanah pulau Jawa iki nek wong nglakoni tirakat pasa Senin Kamis kanthi patang puluh dina, ya ngger ya

Nek aksara Jawa bisa dipecah dadi patang puluh cara

Oleh karena di tanah pulau Jawa ini orang menjalani puasa Senin Kamis empat puluh hari lamanya, maka aksara Jawa pun dapat diurai menjadi empat puluh bagian. 
Nek aksara Jawa aksara 'HA' bisa muni urip ana urip, urip iku ora ana kang nguripi

Urip yen urip langgeng ora kena ing pati nguripi sing kabehing kahanan hananira sejatine wahananingsun

Adapun aksara ' $H A$ ' dapat dimaknai 'Hidup atau hadir. Ada hidup (kehidupan). Allah ada tanpa ada yang menghadirkan. Allah kekal kehadirannya menghidupi semua makhluk yang ada sebagai wahana kehadiranNya.

Kaping loro nek aksara 'NA', nur nur ing gusti dumunung ana sipate menungsa. Najan kasat mata pesti ana. Aksara kedua 'NA' yang maknanya 'cahaya Allah berada pada sifat manusia. Meski tak tampak namun nyata ada'.

Kaping telu nek aksara 'CA', cahya-cahyaning Gusti. Dumunung ana sipate menungsa carme nyang yekti tan cetha wineka. Aksara ketiga ' $C A$ ' yang maknanya 'cahaya Allah berada pada diri manusia namun justru sering diabaikan'.

Kaping papat aksara ' $R A$ ', rahing Gusti dumung ana sipate menungsa. Rasakna karepe lan anggo nira. Aksara keempat ' $R A$ ' yang maknanya 'roh (dzat) Allah ada pada manusia, maka rasakan dan turutilah kehendakNya'.

Kaping lima nek aksara 'KA', kumpul-kumpuling Gusti dumunung ana sipate menungsa kawruh hana iwa kangsi kurang-kurang wong weka. Aksara kelima 'KA' yang maknanya 'Tuhan beserta sifat-sifatNya ada pada diri manusia, maka ketahuilah dan jangan sampai engkau ceroboh'.

Kaping enem aksara 'DA', jagad ing Gusti dumunung ana sipate manungsa. Dadi sak sarian sira ora waspada, ya mas ngono. Aksara keenam 'DA' yang maknanya 'semesta ciptaan Tuhan ini sungguh ada di dalam diri manusia hanya saja engkau tidak awas melihatnya.

Kaping pitu nek aksara 'TA', tetes ing Gusti dumunung ana sipate manungso tamatna sabraning eyang sasmita. Aksara ketujuhbelas ' $T A$ ' yang maknanya 'tetesan atau percikan dzat Tuhan ada pada manusia, maka perhatikanlah semua tanda-isyarat itu'.

Kaping wolu nek aksara 'SA', siji Gusti Allah siji ora ana kang madani. Saking nyebar tumite surasa sasmitane jokongsi bisa krasa. Aksara kedelapanbelas 'SA' yang maknanya 'bahwa Tuhan itu esa (tunggal) dan tidak ada sekutu-Nya maka bacalah isyaratNya sehingga paham'. 
Kaping sanga nek aksara 'WA', wujud wujud ing gusti dumunung ana sipate manungsa. Yen wis ana wur weteng sangang sasi lahir jabang bayi waring tunggal rumesep tan wal. Waspadakna wong wati kang siragawa. Aksara kesembilan 'WA' yang maknanya 'wujud Tuhan ada pada manusia. Dari sejak di dalam kandungan sembilan bulan lalu lahir hingga mati, perhatikanlah apa yang selalu engkau bawa selama itu?'

Kaping sepuluh nek aksara 'LA', langgeng selawase liwat gawat praptaning wangsa yen ilang lalekna yen siroraning tumekaning kalih. Aksara kesepuluh 'LA' yang maknanya 'kekal selamanya meski diuji cobaan ikhlaskanlah sepenuh hati'. Kaping sewelas nek aksara 'PA', papan-papane Gusti Allah ngebaki jagad wati sasar tanwun wagiya papa. Aksara kesebelas ' $P A^{\prime}$ ' yang maknanya 'tempat Tuhan itu memenuhi semesta, maka mereka yang mati kafir pasti menderita'.

Kaping ya kuwi rolas aksara 'DHA', dhawuh-dhawuh ing Gusti dumunung ana sipate Adam ya kuwi menungsa. Kang tumut jangkaning jejenak jejempring wiwarja, ya mas ya ngger. Aksara keduabelas 'DHA' yang maknanya 'bahwa ayat Tuhan ada pada diri manusia dan akan terus bersamanya ke mana pun ia pergi'.

Kaping telulas aksara ' $J A^{\prime}$ ', jangkaning jejenak jejempring warja sak nalika. Aksara ketigabelas ' $J A^{\prime}$ yang maknanya 'ke mana pun arah tujuan hidup manusia'.

Kaping patbelas nek aksara 'YA', Yitma dhahuwe Allah Gusti Allah tansah nyekseni karepe manungsa. Nek sing ala klawan sing becik ngagem pangandikan. Ya yitma ana yitma tempralaya, ya mas ya ngger. Aksara keempatbelas ' $Y A$ ' yang maknanya 'ayat Tuhan selalu menjadi saksi keinginan manusia. Si Buruk berkata kepada si Baik, “Wahai Badan, marilah kita menuju kebinasaan'.

Kaping limalas nek aksara 'NYA', nyata ikhlas pasrah marang Gusti pangerane. Aksara kelimabelas 'NYA' yang maknanya 'sungguh ikhlas berserah diri ke hadirat Tuhan'.

Kaping nembelas nek aksara 'MA', yowis kena diarani mapan. Mapane Gusti Allah ngebaki jagad pati sasar tanwun magiya papa. Aksara keenambelas ' $M A$ ' yang maknanya 'kekuasaan Tuhan melingkupi semesta tak terkecuali neraka'. 
Kaping pitulas aksara 'GA', ya kena diarani gaib dipunggul ping Gusti dumunung ana sipate menungsa. Sing diarani kawruh hana iwa kangsi kurang wong weka, ya mas ya ngger. Aksara ketujuhbelas ' $G A^{\prime}$ yang maknanya 'rahasia Tuhan ada pada diri manusia. Maka ketahuilah. Jangan sampai abai dan kurang teliti'.

Kaping wolulas aksara 'BA', babar-babaring menungsa. Saka nggon uriping Gusti bali murba wasisa ing njero njaba. Aksara kedelapanbelas ' $B A^{\prime}$ yang maknanya 'segenap keberadaan manusia sejak tiada menjadi ada dan kembali tiada sungguh berada dalam kekuasaan Tuhan tak luput sedikitpun'.

Kaping sangalas nek aksara 'THA', thukul-thukule gaib saka kersane Gusti. Ana paribebasasan adoh tanpa omongan cedak tanpa senggolan, ya mas ya ngger. Aksara kesembilanbelas 'THA' yang maknanya 'segala kegaiban yang timbul dan disadari manusia adalah kehendak Tuhan. Ada perumpamaan jauh tak bersapa dekat tak bersentuhan'.

Kaping rong puluh nek aksara 'NGA' ngalam kang gumilang punggul ping Gusti gumilang ing Gusti. Ana rupa mencorong tan kena digrayang. Gedhene sak mrica-mrica dinumput, ya mas ya ngger. Dipunggul ping gusti kebak nista sak nali$k a$, ya mas ya. Aksara keduapuluh 'NGA' yang maknanya 'alam yang berdering kemilaunya adalah kemilau dzat Tuhan. Ada rupa menyilaukan namun dapat dapat diraba. Besarnya sejumputan merica. Neraka Tuhan sungguh dipenuhi nista manusia'.

Jika diperhatikan ajaran tersebut adalah pengembangan dari ajaran Walisongo saat menyebarkan agama Islam di pulau Jawa sekitar abad 15. Dikutip dari Siswoharsono dalam Purwadi ${ }^{11}$, ajaran Walisongo tersebut ialah.

Pangeran itu siji, ana ing ngendi papan, langgeng, sing nganakake jagad iki saisine, dadi sesembahane wong sa'alam kabeh, nganggo carane dhewe-dhewe.

Pangeran iki ana ing ngendi papan; aneng sira uga ana Pangeran, nanging aja sira wani ngaku Pangeran.

Pangeran iki adoh tanpa wangenan, cedhak tanpa senggolan.

11 Purwadi Purwadi, “Kearifan Sufisme dalam Islami Jawa," IBDA` : Jurnal Kajian Islam dan Budaya 9, no. 1 (January 3, 2011): 113-25, https:// doi.org/10.24090/ibda.v9i1.33. 
Pangeran iki langgeng, tan kena kinaya ngapa, sangkan paraning dumadi.

Pangeran iki bisa maujud, nanging wewujudan iki dudu Pangeran.

Pangeran iki kuwasa tanpa piranti, akarya alam saisine, kang katon lan kang ora kasat mata.

Pangeran iku ora mbedak-mbedakake kawula.

Pangeran iku Maha Welas lan Maha Asih; hayuning bawana marga saka kanugrahaning Pangeran.

Pangeran iki Maha Kuwasa; pepesthen saka karsaning Pangeran ora ana sing bisa murungake.

Terjemahan

Tuhan itu satu, ada di mana-mana, abadi, pencipta alam seisinya, dan menjadi sesembahan manusia sejagad raya, dengan memakai tata caranya masing-masing.

Tuhan itu ada di mana-mana, juga ada pada dirimu, tapi jangan engkau berani mengaku dirimu Tuhan.

Tuhan itu jauh tanpa ada batasnya, dan dekat sekali tapi tidak dapat bersentuhan.

Tuhan itu abadai, tidak dapat digambarkan perwujudan-Nya, merupakan sebab yang pertama dan merupakan tujuan terakhir dari segala ciptaan yang ada.

Tuhan itu dapat berwujud, tapi perwujudan itu bukanlah Tuhan.

Tuhan itu berkuasa tanpa menggunakan alat apapun; pencipta alam seisinya, baik yang tampai maupun tidak tampak.

Tuhan itu tidak membeda-bedakan makhluk.

Tuhan itu Maha Rahim dan Maha Kasih, dan kebahagiaan semesta ini adalah anugerah Tuhan.

Tuhan itu Maha Kuasa, tidak ada yang dapat menggagalkan kepastian atas kehendak Tuhan.

Beberapa ajaran Islam yang selaras dalam pertunjukan kentrung dengan ajaran Walisongo adalah sebagai berikut.

a. Tuhan itu satu, ada di mana-mana, abadi, pencipta alam seisinya, dan menjadi sesembahan manusia sejagad raya. Dalam kentrung ada lam- 
bang bunyi 'hananingsun' yang berarti kesaksian wujud Allah. 'bahwa Tuhan itu esa (tunggal) dan tidak ada sekutu-Nya maka bacalah isyaratNya sehingga paham.

b. Tuhan itu ada di mana-mana, juga ada pada dirimu, tapi jangan engkau berani mengaku dirimu Tuhan. Dalam kentrung terdapat kalimat "semogalah dapat dijadikan tahapan, tahapan agar menyatu, menyatu/ melekat kepada bayangan (hakikat) Tuhan, bayangan (hakikat) Tuhan tampak jelas, langgeng lestari berdarma bagi sesama. 'Nur Allah berada pada sifat manusia. Meski tak tampak namun nyata ada'. 'Cahaya (nur) Allah berada pada diri manusia namun justru sering diabaikan. 'Roh (dzat) Allah ada pada manusia, maka rasakan dan turutilah kehendakNya'. 'Tuhan beserta sifat-sifat-Nya ada pada diri manusia, maka ketahuilah dan jangan sampai engkau ceroboh'

c. Tuhan itu abadi, tidak dapat digambarkan perwujudan-Nya, merupakan sebab yang pertama dan merupakan tujuan terakhir dari segala ciptaan yang ada. Dalam kentrung "Allah hidup atau hadir. Ada hidup (kehidupan). Allah ada tanpa ada yang menghadirkan. Allah kekal kehadirannya menghidupi semua makhluk yang ada sebagai wahana kehadiran-Nya.

d. Tuhan itu tidak membeda-bedakan makhluk. Dalam kentrung "rasa persamaan di dalam kemanusiaan telah dijiwai bersama. Segala darma bakti disesuaikan dengan kemampuan pribadi sehingga tidak berlawanan dengan prinsip kesederhanaan dan kejujuran. Selamat dan berhasil seluruh penghuni alam raya. Berbuat demi keselamatan hidup di dunia. Sungguh selalu ingat peduli kepada sesama, sikap kepedulian itu merata melingkupi semesta. Adapun pedomannya ialah berbuat baik semampunya, tanpa dipaksakan dan tanpa rekayasa muslihat." Manusia diminta untuk taat pada Tuhan, menyayangi sesama manusia, dan menyayangi alam. Sehingga semuanya berjalan seimbang karena Tuhan tidak membeda-bedakan makhluknya.

e. Tuhan itu Maha Kuasa, tidak ada yang dapat menggagalkan kepastian atas kehendak Tuhan. Dalam kentrung, "Atas semua perbuatan kita Tuhanlah yang berwenang menentukan ganjarannya. Segenap keberadaan manusia sejak tiada menjadi ada dan kembali tiada sungguh berada da- 
lam kekuasaan Tuhan tak luput sedikitpun', 'Segala kegaiban yang timbul dan disadari manusia adalah kehendak Tuhan. Ada perumpamaan jauh tak bersapa dekat tak bersentuhan'.

Dengan adanya tanda berupa persamaan ajaran yang disampaikan pertunjukan kentrung dengan ajaran Walisongo, berdasarkan makna teks dapat dimaknai bahwa pertunjukan kentrung adalah salah satu kesenian yang sekaligus mempertahankan ajaran Walisongo di tengah-tengah masyarakat yang mulai meninggalkannya.

\section{KESIMPULAN}

Kentrung Blora yang besar dari hajatan satu ke hajatan lain sebagai lambang doa kini juga menjadi sebuah seni pertunjukan kentrung Blora yang sudah bukan hal asing tampil dalam panggung besar di depan khalayak ramai dijadikan salah satu ikon kesenian Blora. Pemerintah yang selalu menampilkan pertunjukan kentrung Blora dalam acara peringatan hari penting seperti hari ulang tahun Blora, hari ulang tahun republik Indonesia yang dirayakan di Blora, dan festival kesenian asli Blora adalah wujud mengupayakan agar kesenian ini tetap lestari yaitu dengan memunculkannya sebagai sebuah seni pertunjukan yang besifat hiburan bagi masyarakat. Kendati demikian, perubahan wujud secara sistem kentrung Blora di masyarakat tidak membuat makna atau nilai yang terkandung di dalamnya mengalami perubahan suatu apapun.

Nilai yang tidak mengalami perubahan tersebut ialah nilai edukatif pada pertunjukan kentrung Blora yaitu ajaran ilmu pegangan hidup yang selaras dengan ajaran Walisongo saat disebarkan di pulau Jawa sejak abad 15 dikemas dalam sebuah cerita babad yang dilengkapi dengan nasihat, doa, dan pantun sebagai warna dalam pertunjukan yang menghibur para penontonnya. Ajaran tentang ilmu pegangan hidup tersebut bernama "sipat rong puluh" atau "sifat dua puluh" selaras dengan aksara Jawa yang berjumlah dua puluh HA NA CA RA KA DA THA SA WA LA MA GA BA THA NGA PA DHA JA YA NYA. Namun ada dua kali penjabaran "sipat rong puluh" dengan penjelasan berbeda sehingga jumlahnya menjadi empat puluh poin dalam ilmu pegangan hidup Ke empat puluh poin yang dijabarkan sebagai 
ilmu pegangan hidup tersebut secara khusus adalah untuk seorang muslim. Tetapi karena masih erat kaitannya dengan kepercayaan Jawa yang selalu menjaga keseimbangan antara manusia, Tuhan, dan alam, ilmu pegangan hidup tersebut dapat pula diterapkan secara umum bagi setiap manusia untuk memperoleh kehidupan yang seimbang.

\section{DAFTAR PUSTAKA}

Al-Hasan, Yusuf Muhammad. Pendidikan Anak Dalam Islam. Jakarta: Darul Haq, 1998.

Circumcision, Policy Statenent. "Pediatrics" 130 (September 2012).

Dewi, Arum Kusuma, Sriyanto, and Suharti. "Fungsi Kesenian Kentrungan

Di Nagari Sialanggaung Kec. Koto Baru Kab. Dharmasraya." Laga-Laga Vol. 4, no. 2 (September 2018): 187-98.

Harwanto, Dody Candra, and Sunarto. “Bentuk Dan Struktur Kesenian Kentrung Di Jepara." Resital Vol. 19, no. 1 (April 2018): 35-45.

Inayah, Eva Nur. "Bentuk, Makna, Dan Fungsi Tembang-Tembang Kentrung Bate Di Kabupaten Tuban." Universitas Airlangga, 2015.

Prier, Karl Edmund. Kamus Musik. Yogyakarta: Pusat Musik Liturgi, 2011. Purwadi, Purwadi. "Kearifan Sufisme dalam Islami Jawa." IBDA' : Jurnal Kajian Islam dan Budaya 9, no. 1 (January 3, 2011): 113-25. https:// doi. org/10.24090/ibda.v9i1.33.

Sani, Anwar, Tirmidzi As-Shidiq, and Ahmad Jameel. Belajar Dari Ustadz Yusuf Mansur,. Jakarta: Gramedia, 2013.

Thohari, Fuad. Hadis Ahkam: Kajian Hadis-Hadis Hukum Pidana Islam (Hudud, Qishash, Dan Ta'zir). Yogyakarta: Deepublish, 2016.

Zarman, Wendi. Ternyata Mendidik Anak Cara Rasulullah Mudah \& Efektif. Jakarta: Kawan Pustaka, 2017.

Zen, Patra, and Daniel Hutagalung. Panduan Bantuan Hukum Di Indonesia: Pedoman Anda Memahami Dan Menyelesaikan Masalah Hukum,. Jakarta: Yayasan Obor Indonesia, 2007. 